\title{
Enucleation and development of cluster headache: a retrospective study
}

\author{
Peter Sörös*1,3, Oanh Vo ${ }^{1}$, Heinrich Gerding ${ }^{2}$, Ingo W Husstedt ${ }^{1}$ and \\ Stefan Evers ${ }^{1}$
}

Address: ${ }^{1}$ Department of Neurology, Münster University Hospital, Albert-Schweizer-Strasse 33, 48149 Münster, Germany, ${ }^{2}$ Department of Ophthalmology, Münster University Hospital, Domagkstrasse 15, 48149 Münster, Germany and 32Department of Imaging Research, Sunnybrook and Women's College Health Sciences Centre, 2075 Bayview Avenue, Toronto, Ontario, M4N 3M5, Canada

Email: Peter Sörös* - soros@mac.com; Oanh Vo - Oanhvo@web.de; Heinrich Gerding - gerdinh@unimuenster.de; Ingo W Husstedt - husstedt@unimuenster.de; Stefan Evers - everss@unimuenster.de

* Corresponding author

Published: 22 March 2005

BMC Neurology 2005, 5:6 doi:10.1 186/147/-2377-5-6

This article is available from: http://www.biomedcentral.com/l47/-2377/5/6

(c) 2005 Sörös et al; licensee BioMed Central Ltd.

This is an Open Access article distributed under the terms of the Creative Commons Attribution License (http://creativecommons.org/licenses/by/2.0), which permits unrestricted use, distribution, and reproduction in any medium, provided the original work is properly cited.
Received: 22 September 2004

Accepted: 22 March 2005

\begin{abstract}
Background: Cluster headache $(\mathrm{CH})$ is a neurovascular, primary headache disorder. There are, however, several case reports about patients whose $\mathrm{CH}$ started shortly after a structural brain disease or trauma. Motivated by a patient who developed $\mathrm{CH} 3$ weeks after the removal of an eye and by similar case reports, we tested the hypothesis that the removal of an eye is a risk factor for $\mathrm{CH}$.
\end{abstract}

Methods: A detailed headache questionnaire was filled out by I 2 patients on average 8 years after enucleation or evisceration of an eye.

Results: While $21 \%$ of these patients experienced previously unknown headaches after the removal of an eye, no patient fulfilled the diagnostic criteria for $\mathrm{CH}$.

Conclusion: Our data does not suggest that the removal of an eye is a major risk factor for the development of $\mathrm{CH}$.

\section{Background}

Cluster headache $(\mathrm{CH})$ is characterized by severe attacks of unilateral pain and cranial autonomic dysfunction [1]. The pain is usually felt in and around the orbita or adjacent areas of the head (Fig. 1). CH attacks last 15-180 minutes and occur, during a cluster period, from once every other day to several times a day. The symptoms of autonomic dysfunction are always ipsilateral to the pain and can involve the eye (conjunctival injection, lacrimation, miosis, ptosis, eyelid edema), the nose (nasal congestion, rhinorrhea), and the face (sweating) [1]. The exact pathophysiology of $\mathrm{CH}$ is, more than 250 years after the first description of episodic $\mathrm{CH}$ by Gerhard van Swieten in 1745 [2], still unresolved. Several convergent lines of evidence suggest that $\mathrm{CH}$ is a primary neurovascular disorder (for review see [3]). The hypothalamus is supposed to be involved in the pathogenesis of $\mathrm{CH}$ and might even be pivotal for the timing of cluster periods and single attacks [4].

Challenging the notion of an exclusively primary headache disorder, several reports described the onset of $\mathrm{CH}$ during or shortly after traumatic brain injury $[5,6]$ or structural brain disease (reviewed in $[7,8]$ ). In many of 


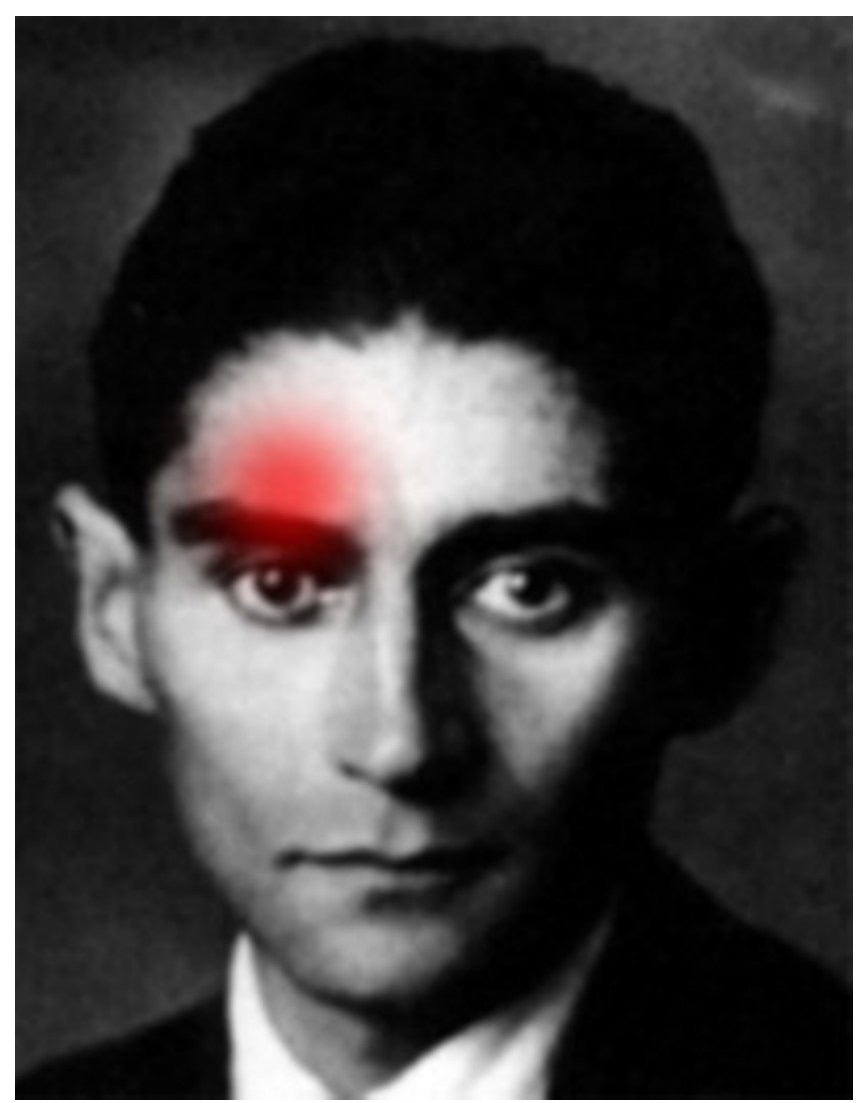

Figure I

Pain in cluster headache. The location of intense pain, usually orbital or supraorbital, in a $\mathrm{CH}$ attack, overlayed onto the portrait of Franz Kafka (1924). Kafka suffered from extremely severe headache attacks, possibly $\mathrm{CH}$ [39].

these reports, vascular disorders (e.g. arterio-venous malformations [9,10], aneurysms [11], dissections [12], or fistulas [13] of the cranial vasculature) were associated with the onset of $\mathrm{CH}$. In other patients, intracranial neoplasms (e.g. meningeomas [14], adenomas [15]) or local inflammatory processes $[16,17]$ were seen in connection with the beginning of $\mathrm{CH}$. All reports on putative secondary $\mathrm{CH}$ face the difficult question whether there is a causal relationship or a mere coincidence between $\mathrm{CH}$ and the preceding brain injury or disease. The International Classification of Headache Disorders suggests to code a headache with the characteristics of a primary headache (e.g. $\mathrm{CH}$ ) as a secondary headache if it occurs for the first time and in close temporal relation to another disorder that is a known cause of headache [1]. We follow the phenomenologic classification of the International Headache Society (IHS) [18] and regard all headaches with the symptomatology of $\mathrm{CH}$ and developing in a close tempo- ral relationship to a brain injury or disease as secondary headaches.

In addition to the aforementioned patients, we saw a 37 year-old man who fulfilled the IHS criteria for a secondary $\mathrm{CH}$. He developed strictly right-sided episodic $\mathrm{CH} 3$ weeks after the removal of his right eye bulb [19]. The patient not only fulfilled the diagnostic criteria for $\mathrm{CH}[1]$, but also responded to standard acute and prophylactic $\mathrm{CH}$ therapy. At least another 5 patients, all of them male, could be identified in the literature who developed $\mathrm{CH}$, either episodic or chronic, after the removal of the eye bulb [19]. Episodic CH originated in a 45 -year-old man one year after maxillectomy and exenteration due to a squamous cell carcinoma [20]. In other patients, however, $\mathrm{CH}$ developed up to 18 years after surgery [21]. Despite the suggestive chronology in our patient with a latency between surgery and first $\mathrm{CH}$ attack of only 3 weeks, it remained unclear if the removal of the eye influenced the development of $\mathrm{CH}$ or if both events were unrelated. To test the hypothesis that removal of an eye is a risk factor for $\mathrm{CH}$ we conducted a retrospective survey among individuals whose eye had to be resected.

\section{Methods}

To identify patients who underwent the removal of an eye, the clinical records of all inpatients admitted to the Department of Ophthalmology, Minister University Hospital between 1986 and 1995 were reviewed. In total, 332 patients had enucleation or evisceration of one eye in the specified time frame. All patients received a detailed questionnaire via mail asking about the occurrence and clinical presentation of headaches before and after the removal of the bulb (33 questions in total). The questionnaire was developed by the authors and included, amongst others, questions about the location, the quality, the duration of individual headache attacks, the occurrence of cluster periods, and the typical autonomic features of $\mathrm{CH}$. The questionnaire included all diagnostic criteria for $\mathrm{CH}$ as described in the International Classification of Headache Disorders [1], but it was not formally validated. The patients were asked to return the completed questionnaire in a pre-paid envelope by mail. Medical records were consulted for personal data, the ophthalmologic diagnosis leading to the removal of the eye, and the operative technique used. A different aspect of this study regarding the prevalence and phenomenology of phantom experiences after removal of the eye was published previously [22]. The 37-year-old man who developed $\mathrm{CH} 3$ weeks after removal of the ipsilateral eye, reported by us [19], was not included in the study population presented here because surgery was performed in an external hospital. A post-hoc analysis of statistical power was performed to assess the minimum effect size observable by the available sample size using the statistical package $\mathrm{R}$ for Mac OS X [23]. This 
analysis was based on the prevalence of $\mathrm{CH}$ found in two recent epidemiological studies [24,25]. The required statistical power was set to 0.8 and the significance level to 0.05 .

\section{Results}

One hundred twelve patients (78 men and 34 women) completed our questionnaire and were included in the data analysis (response rate, $33.7 \%$ ). The average age at the time of eye removal was $48 \pm 21$ years, and the average latency between eye removal and completing the questionnaire was $8 \pm 3$ years (range, 3-19 years). The major reasons for removal of the eye bulb were eye trauma $(n=$ $40,36 \%)$, and malignant $(\mathrm{n}=22,20 \%)$ or non-malignant eye diseases $(n=50,44 \%)$. Enucleation (removal of the globe with sparing of the extraocular muscles [26] was performed in 104 patients (93\%), and evisceration (removal of the contents of the globe with the sclera and the extraocular muscles left intact) was done in 8 patients (7\%). After the removal of the bulb, 24 patients $(21 \%)$ experienced previously unknown headaches. Although 13 of those patients reported strictly unilateral headaches (usually ipsilateral to the removed eye bulb), the characteristic autonomic symptoms of cluster headache and the typical temporal pattern of headache attacks were absent in all of those patients. None of the patients thus fulfilled the diagnostic criteria for $\mathrm{CH}$ [1]. The power analysis revealed that a $\mathrm{CH}$ prevalence of 5.5 or more in our group of 112 patients would have resulted in a significant increase of $\mathrm{CH}$ prevalence (based on a population-wide $\mathrm{CH}$ prevalence of 56/100,000 [25]). Based on a $\mathrm{CH}$ prevalence of $326 / 100,000$ [24], a prevalence of 6.2 or more would have been significant.

\section{Discussion}

This retrospective study on 112 patients could not identify individuals who developed CH 3 - 19 years after removal of an eye bulb. During enucleation, the predominant technique used in our patients, the globe has to be separated from all orbital tissue, including the external eye muscles and the optic nerve (Fig. 2) [26]. The eye is innervated by the optic nerve, the nasociliary nerve and the sympathetic and parasympathetic fibers. This led us to the hypothesis that lesions of the autonomic network might induce secondary $\mathrm{CH}$ in patients after enucleation [19]. Similar mechanisms have been discussed in a patient with secondary $\mathrm{CH}$ due to an intracranial inflammatory pseudotumor in the posterior fossa [27]. Our result, however, does not provide evidence for the notion that a first $\mathrm{CH}$ attack after the removal of the bulb, as observed previously $[19,20]$, is triggered or at least facilitated by the irritation of trigemino-autonomic nervous structures during surgery and wound healing. The techniques of evisceration and enucleation spare parts of the orbita (especially the external eye muscles) and usually do not affect the cra-

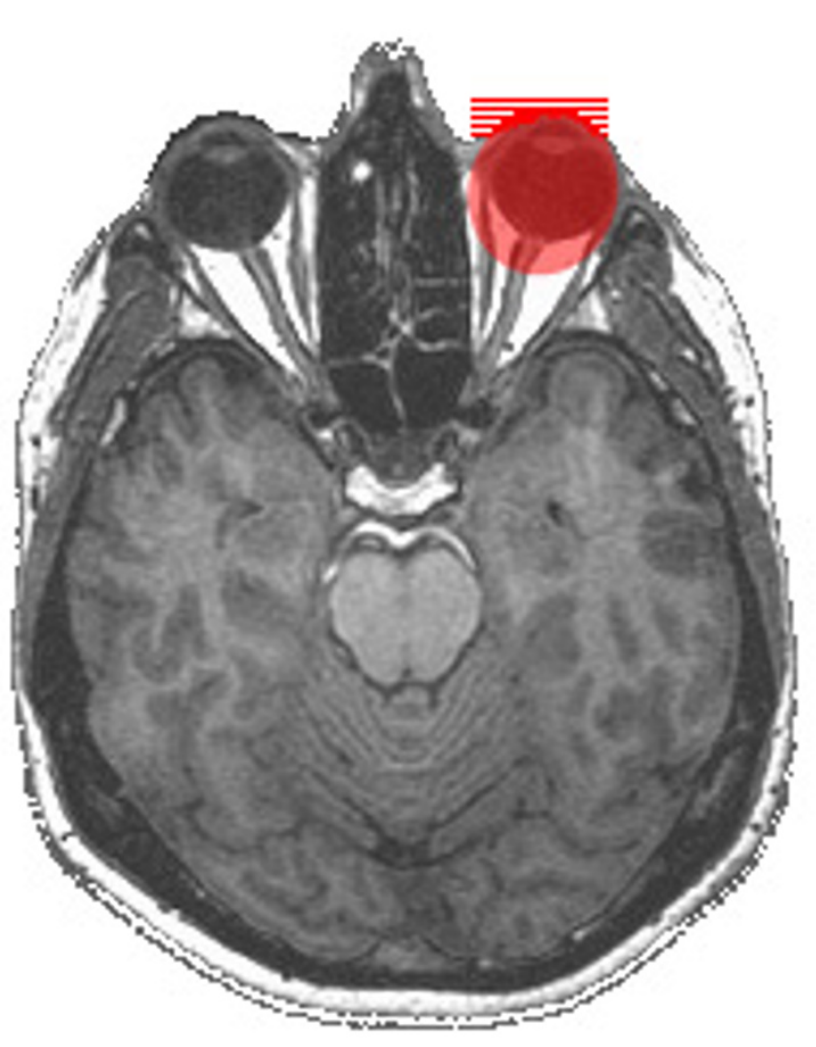

\section{Figure 2}

Orbital anatomy. High-resolution axial TI-weighted native MRI of a volunteer without structural abnormalities at 3.0 Tesla. Structures removed during enucleation (globe, part of the optic nerve, insertions of the external eye muscles) are highlighted by the red ellipse.

nial nerves III, IV, and VI. During exenteration, on the other hand, the entire orbital content has to be removed. Patients with exenteration were not included in this study because this technique is used less frequently and mainly in cancer patients (which makes longer follow-up periods difficult). Patients with exenteration might be especially prone to develop $\mathrm{CH}$ because this procedure results in extensive damage of nervous tissue. As $\mathrm{CH}$ pain is often located in or around the orbita and the autonomic symptoms of $\mathrm{CH}$ usually involve the eye, it has been speculated if $\mathrm{CH}$ can occur without an ipsilateral eye. Patients developing ipsilateral $\mathrm{CH}$ after the removal of an eye [19] irrespective of the temporal relationship between these two events, clearly demonstrate that the eye and the surrounding tissues are not essential for the pathogenesis of $\mathrm{CH}$.

CH usually develops between 20 and 45 years [28], with a mean age of onset of about 29 years $[29,30]$. $\mathrm{CH}$, however, can start much later in life. Patients with a first $\mathrm{CH}$ 
attack at the age of 83 years and 75 years have been described [31]. As the mean age in our patients ( 48 years) is higher than the mean age of onset of $\mathrm{CH}$, one might speculate that, in many of our patients, the removal of the eye was done when they were less susceptible for the development of $\mathrm{CH}$. We do not suppose that the age difference between our sample of patients after eye removal and patients with first $\mathrm{CH}$ attack significantly influenced the result of this study. The reports on patients who developed $\mathrm{CH}$ in their 70ies and 80ies demonstrate that higher age does not prevent the development of $\mathrm{CH}$. Moreover, many patients with secondary $\mathrm{CH}$ were older than the average age of onset of primary $\mathrm{CH}$. The age of onset of the 5 patients with a first $\mathrm{CH}$ attack after removal of the eye was 36 years [19].

The presented study, however, has its limitations. The retrospective, questionnaire-based design might underestimate the prevalence of $\mathrm{CH}$. Descriptions of the main symptoms of $\mathrm{CH}$, however, either in questionnaires or letters, have proven to be useful in several epidemiological studies on $\mathrm{CH}[25,32-36]$ and take advantage of the distinct diagnostic criteria and the impressive nature of $\mathrm{CH}$. The use of short self-adminstered questionnaires for screening larger populations has also been validated in migraine $[37,38]$. Our study was designed to screen our population via a questionnaire and then to verify each probable diagnosis of $\mathrm{CH}$ with a detailed interview and a comprehensive neurological examination (no patient, however, reported the main features of $\mathrm{CH}$, short attacks of unilateral, severe headaches in bouts). Individuals with infrequent and mild bouts, however, might not recall past $\mathrm{CH}$ attacks while responding to a questionnaire. In addition, the relatively low response rate (34\%) might have influenced the present results. On the one hand, patients with $\mathrm{CH}$ might be hidden in the group of individuals not responding to our questionnaire. On the other hand, patients with $\mathrm{CH}$ are probably more willing to respond to a survey targeted at their symptoms than patients with other forms of headache or without headaches at all. In general, a prospective study which includes patients before the removal of an eye, follows them over years and then compares the outcome to a control group (i.e., a cohort study) would be more effective for the study of a disease's risk factors. In addition, $\mathrm{CH}$ is rare with a prevalence of less than $1 \%$. Investigating possible risk factors for rare disorders requires large sample or effect sizes. Our sample size is large enough to yield statistical significance for a $\mathrm{CH}$ prevalence of $5.5 \%$ in our group (or $6.2 \%$, depending on the assumed population-wide $\mathrm{CH}$ prevalence), but might be too small to detect a slight increase of $\mathrm{CH}$ among patients after removal of an eye.

\section{Conclusion}

Our data does not suggest that the removal of the globe is a major risk factor for the development of $\mathrm{CH}$. We cannot exclude the possibility that enucleation is associated with a small increase in $\mathrm{CH}$ prevalence.

\section{Authors' contributions}

All authors participated in designing the study and constructing the headache questionnaire. PS prepared the manuscript and performed the statistical analyses. OV contacted the patients, collected the data, and assisted with data analysis. HG participated in data collection, interpretation of the results, and drafting the manuscript. IWH and SE participated in interpretation of the results and in preparing the manuscript. All authors have read and approved the final manuscript.

\section{Acknowledgements}

The authors thank all patients who participated in this study. The authors are also grateful to two reviewers whose comments improved the first version of this article.

\section{References}

I. The International Classification of Headache Disorders: 2nd edition. Cephalalgia 2004, 24(Suppl I):9-160.

2. Isler H: Episodic cluster headache from a textbook of 1745: van Swieten's classic description. Cephalalgia 1993, I3(3): $172-174$.

3. Goadsby PJ: Pathophysiology of cluster headache: a trigeminal autonomic cephalgia. Lancet Neurol 2002, I (4):25I-257.

4. May A: Headache: lessons learned from functional imaging. $\mathrm{Br}$ Med Bull 2003, 65:223-234.

5. Reik LJ: Cluster headache after head injury. Headache 1987, 27(9):509-510.

6. Turkewitz LJ, Wirth O, Dawson GA, Casaly JS: Cluster headache following head injury: a case report and review of the literature. Headache 1992, 32(10):504-506.

7. Sörös P, Frese A, Husstedt IW, Evers S: Cluster headache after dental extraction: implications for the pathogenesis of cluster headache? Cephalalgia 200I, 2 I(5):619-622.

8. Carter DM: Cluster headache mimics. Curr Pain Headache Rep 2004, 8(2): 133-139.

9. Mani S, Deeter J: Arteriovenous malformation of the brain presenting as a cluster headache $-\mathbf{a}$ case report. Headache 1982 , 22(4): $184-185$.

10. Muñoz C, Diez-Tejedor E, Frank A, Barreiro P: Cluster headache syndrome associated with middle cerebral artery arteriovenous malformation. Cephalalgia 1996, 16(3):202-205.

11. West P, Todman D: Chronic cluster headache associated with a vertebral artery aneurysm. Headache 1991, 31(4):210-212.

12. Cremer PD, Halmagyi GM, Goadsby PJ: Secondary cluster headache responsive to sumatriptan. I Neurol Neurosurg Psychiatry 1995, 59(6):633-634.

13. Seijo Martinez M, Castro del Rio M, Cervigon E, Conde C: Symptomatic cluster headache: presentation of 2 cases. Neurologia 2000, 15(9):406-410.

14. Taub E, Argoff CE, Winterkorn JM, Milhorat TH: Resolution of chronic cluster headache after resection of a tentorial meningioma: case report. Neurosurgery 1995, 37(2):3 |9-2I. discussion $32 \mathrm{I}-2$.

15. Tfelt-Hansen P, Paulson OB, Krabbe AA: Invasive adenoma of the pituitary gland and chronic migrainous neuralgia. A rare coincidence or a causal relationship? Cephalalgia 1982, 2:25-28.

16. Heidegger S, Mattfeldt T, Rieber A, Wikstroem M, Kern P, Kern W, Schreiber H: Orbito-sphenoidal Aspergillus infection mimicking cluster headache: a case report. Cephalalgia 1997, I7(6):676-679. 
17. Sacquegna $T$, D'Alessandro $R$, Cortelli $P$, de Carolis $P$, Baldrati $A$ : Cluster headache after herpes zoster ophthalmicus. Arch Neurol 1982, 39(6):384.

18. Evers S: Die neue IHS-Klassifikation. Hintergrund und Struktur. Schmerz 2004, I 8(5):35I-356.

19. Evers S, Sörös P, Brilla R, Gerding H, Husstedt IW: Cluster headache after orbital exenteration. Cephalalgia 1997, 17(6):680-682.

20. McKinney AS: Cluster headache developing following ipsilateral orbital exenteration. Headache 1983, 23(6):305-306.

21. Prusinski A, Liberski PP, Szulc-Kuberska J: Cluster headache in a patient without a ipsilateral eye. Headache 1985, 25(3): I34-I35.

22. Sörös $P, V_{\circ} O$, Husstedt IW, Evers S, Gerding H: Phantom eye syndrome: Its prevalence, phenomenology, and putative mechanisms. Neurology 2003, 60(9): 1542-1543.

23. R Development Core Team: R: A language and environment for statistical computing. Vienna, Austria 2004 [http://www.Rproject.org].

24. Sjaastad O, Bakketeig LS: Cluster headache prevalence. Vaga study of headache epidemiology. Cephalalgia 2003, 23(7):528-533.

25. Tonon C, Guttmann S, Volpini M, Naccarato S, Cortelli P, D'Alessandro R: Prevalence and incidence of cluster headache in the Republic of San Marino. Neurology 2002, 58(9): 1407-| 409.

26. Moshfeghi DM, Moshfeghi AA, Finger PT: Enucleation. Surv Ophthalmol 2000, 44(4):277-30I.

27. Bigal ME, Rapoport AM, Camel M: Cluster headache as a manifestation of intracranial inflammatory myofibroblastic tumour: a case report with pathophysiological considerations. Cephalalgia 2003, 23(2): | 24-128.

28. Olesen J, Tfelt-Hansen P, Welch K, (eds): The headaches 2 nd edition. Lippincott, Williams Wilkins; 2000.

29. Manzoni GC, Terzano MG, Bono G, Micieli G, Martucci N, Nappi G: Cluster headache - clinical findings in 180 patients. Cephalalgia 1983, 3:21-30

30. Bahra A, May A, Goadsby PJ: Cluster headache: a prospective clinical study with diagnostic implications. Neurology 2002, 58(3):354-36I.

31. Evers S, Frese A, Majewski A, Albrecht O, Husstedt IW: Age of onset in cluster headache: the clinical spectrum (three case reports). Cephalalgia 2002, 22(2): 160-162.

32. Gesztelyi G, Bereczki D: Primary headaches in an outpatient neurology headache clinic in East Hungary. Eur J Neurol 2004, I I(6):389-395.

33. Klapper JA, Klapper A, Voss $\mathrm{T}$ : The misdiagnosis of cluster headache: a nonclinic, population-based, Internet survey. Headache 2000, 40(9):730-735

34. Mitsikostas DD, Thomas A, Gatzonis S, llias A, Papageorgiou C: An epidemiological study of headache among the Monks of Athos (Greece). Headache 1994, 34(9):539-541.

35. Russell MB, Andersson PG, Thomsen LL: Familial occurrence of cluster headache. I Neurol Neurosurg Psychiatry 1995, 58(3):34|-343.

36. Torelli $\mathrm{P}$, Beghi E, Manzoni GC: Cluster headache prevalence in the Italian general population. Neurology 2005, 64(3):469-474.

37. Kallela $M$, Wessman M, Farkkila M: Validation of a migraine-specific questionnaire for use in family studies. Eur J Neurol 200I 8:6I-66.

38. Lipton RB, Dodick D, Sadovsky R, Kolodner K, Endicott J, Hettiarachchi J, Harrison W: A self-administered screener for migraine in primary care: The ID Migraine validation study. Neurology 2003, 6 I(3):375-382.

39. Ekbom T, Ekbom K: Did Franz Kafka suffer from cluster headache? Cephalalgia 2004, 24(4):309-3II.

\section{Pre-publication history}

The pre-publication history for this paper can be accessed here:

http://www.biomedcentral.com/1471-2377/5/6/prepub
Publish with Biomed Central and every scientist can read your work free of charge

"BioMed Central will be the most significant development for disseminating the results of biomedical research in our lifetime. "

Sir Paul Nurse, Cancer Research UK

Your research papers will be:

- available free of charge to the entire biomedical community

- peer reviewed and published immediately upon acceptance

- cited in PubMed and archived on PubMed Central

- yours - you keep the copyright

Submit your manuscript here:

http://www.biomedcentral.com/info/publishing_adv.asp
BioMedcentral 